\title{
FLOOD FORECASTING SYSTEM OF URBAN AREAS IN SOUTH KOREA
}

\author{
YOUNG-IL MOON, JI-HYEOK CHOI, MIN-SEOK KIM \& JUNG-HWAN LEE \\ Department of Civil Engineering, University of Seoul, Seoul, South Korea
}

\begin{abstract}
The needs of safety and the security of the homeland from unexpected natural disasters have been growing among people recently. Flood damages have been recorded every year and those damages are greater than the annual average of 2 billion US dollars since 2000 in South Korea. Due to the rapid growth of urbanization and climate change, the frequency of concentrated heavy rainfall has increased causing urban flood that results in casualties and property damage. Despite the emerging importance of a flooding situation, the studies related to the development of an integrated management system for reducing floods are insufficient in South Korea. In addition, it is difficult to reduce floods effectively without developing integrated operation system taking into account of sewage pipe network configuration with the river level. Since the floods result in increasing damages to infrastructure, as well as life and property, structural and non-structural measures should be urgently established in order to reduce the flood effectively. Therefore, in this study, we developed an integrated flood analysis system that systematized technology to quantify flood risk and flood forecasting in urban areas. The purpose of this study is to introduce integrated Landside-River Combined System by reducing the risk of floods in urban areas using radar and satellite information. Therefore, we developed the flood forecasting system so people can have enough time to evacuate in case of emergency.
\end{abstract}

Keywords: flood risk, inland-river combined flood system, urban flood

\section{INTRODUCTION}

Severe natural disasters, including flooding and landslides, occur repeatedly in the Korean Peninsula due to the heavy rainfall induced by typhoons and localized torrential downpours during the summer season, resulting in considerable casualties as well as severe social and economic loss [1,2]. Throughout the Korean Peninsula, two thirds of the annual precipitation $(1283 \mathrm{~mm})$ is concentrated in the rainy season from June to September, so the risk of flood damage is present every year. Moreover, it has been observed that the frequency of localized heavy rain has greatly increased and the scale of damage tends to be larger in the city of Seoul [3]. Additionally, in Seoul, due to its urbanization, when flood damage occurs in lowland, it will cause enormous human casualties and property damage [4]. Thus, it is needed to make a systematic flood control plan. Therefore, this article is going to introduce the causes of flood damage and flood forecasting system.

\section{MAJOR CAUSES OF FLOOD IN SEOUL}

Flooding that occurs in the city basin causes progressive damage on social infrastructure as well as on human life and property. It is urgent to build measures for both structural and non-structural inland drainage flood prevention that can be effective in defence. The following summarizes the major causes of floods in Seoul and the types of damage.

- Due to recent climate change, localized heavy rain has resulted in flooding.

- The increased of water level in the stream caused poor river drainage of inland basin.

- The flood occurred by the overflow from the river. 


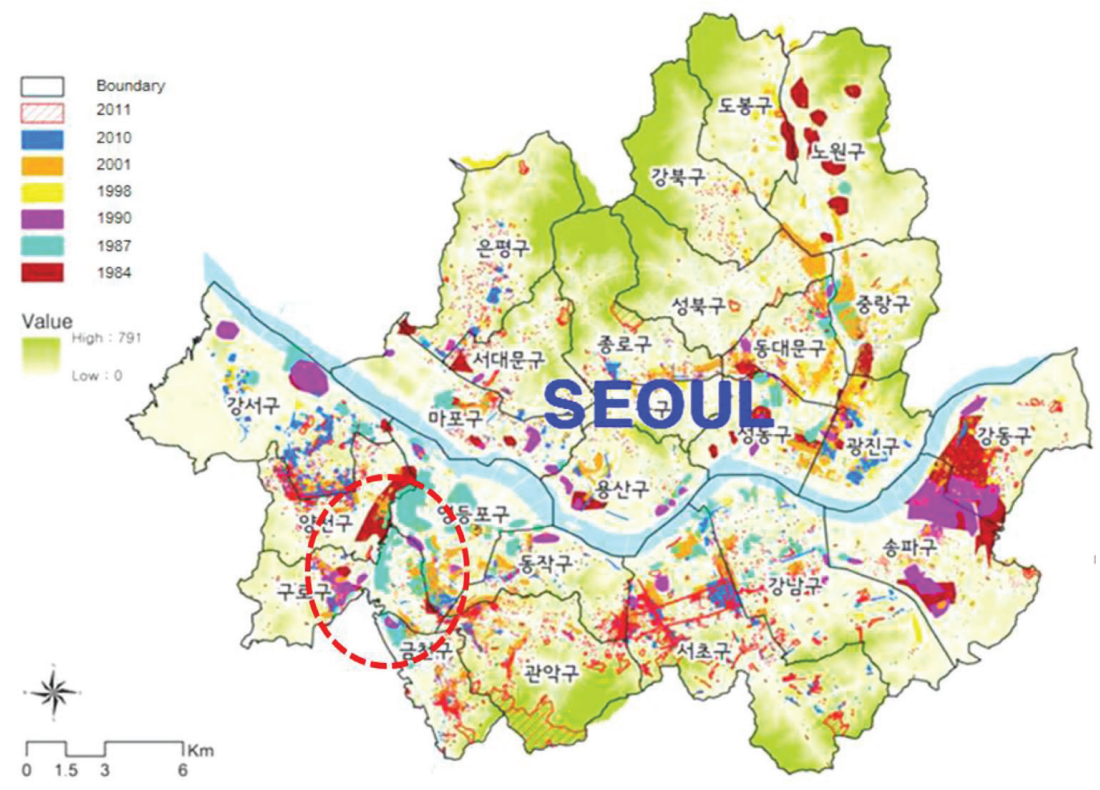

Figure 1: Flood-damaged areas in Seoul (1984-2011).

- Inland damage occurred because of the lack of sewerage capacity as well as capacity of a rain pumping station.

- Various factors including landslides worked complexly.

- The greatest damage was done to river facilities including sewerage and small rivers.

\section{FLOOD FORECASTING SYSTEM OF URBAN AREA}

Through the analysis of the major causes of inundation in Seoul, a system which can alert and forecast urban flooding must be developed to prevent property damage along with casualties. The following figure shows a system framework of flood forecasting system.

The system provide forecast for urban flood through real-time operation. This is a system for analysing river and inland inundation through a short-term rainfall prediction.

The critical technology of system is divided into three parts: (A) forecasting rainfall; (B) constructing sewer networks; and (C) setting up inundation data base.

In the first step, the short-term rainfall forecasting, using the radar data or radar and satellite data were implemented. It can be estimated for 120-min before rainfall prediction with 10-min lead time using the TREC (Tracking Radar Echoes by Correlation) technique.

In the second step, rainfall-runoff model is needed to apply forecasted rainfall. In this study, the runoff analysis of urban basin has used in SWMM 5.1 model. In result of the constructing sewer networks (all basin of Dorim area), the number of sewers is 31,480. The more number of sewers increase, the more analysis run-time of the model increase. If the model is applied to the real-time urban flood forecast using the total sewer network, there is a problem of missing the golden time due to the time spent on analysing the model. Thus, to reduce simulation time of model, sewer network simplification by automatic simplification technology must be developed. 


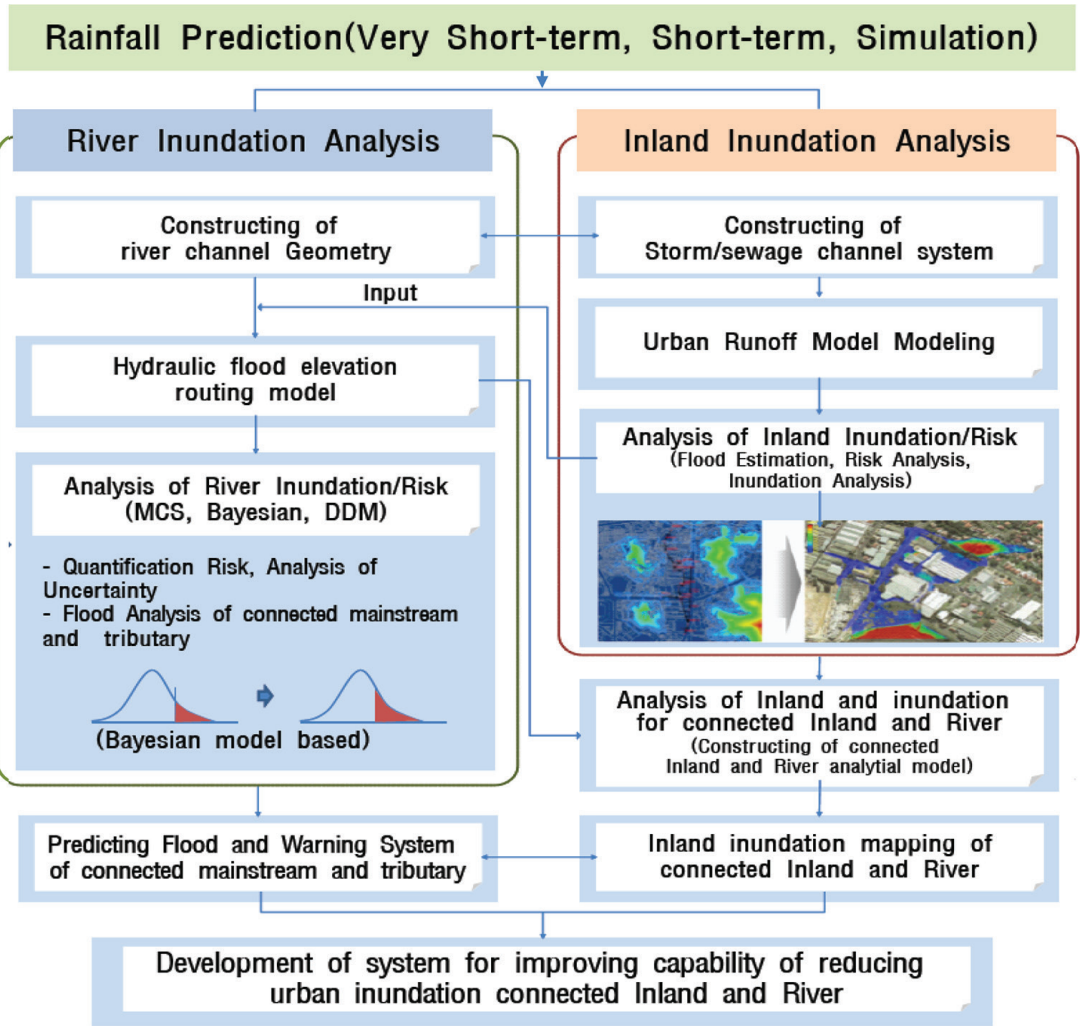

Figure 2: Framework of flood forecasting system.

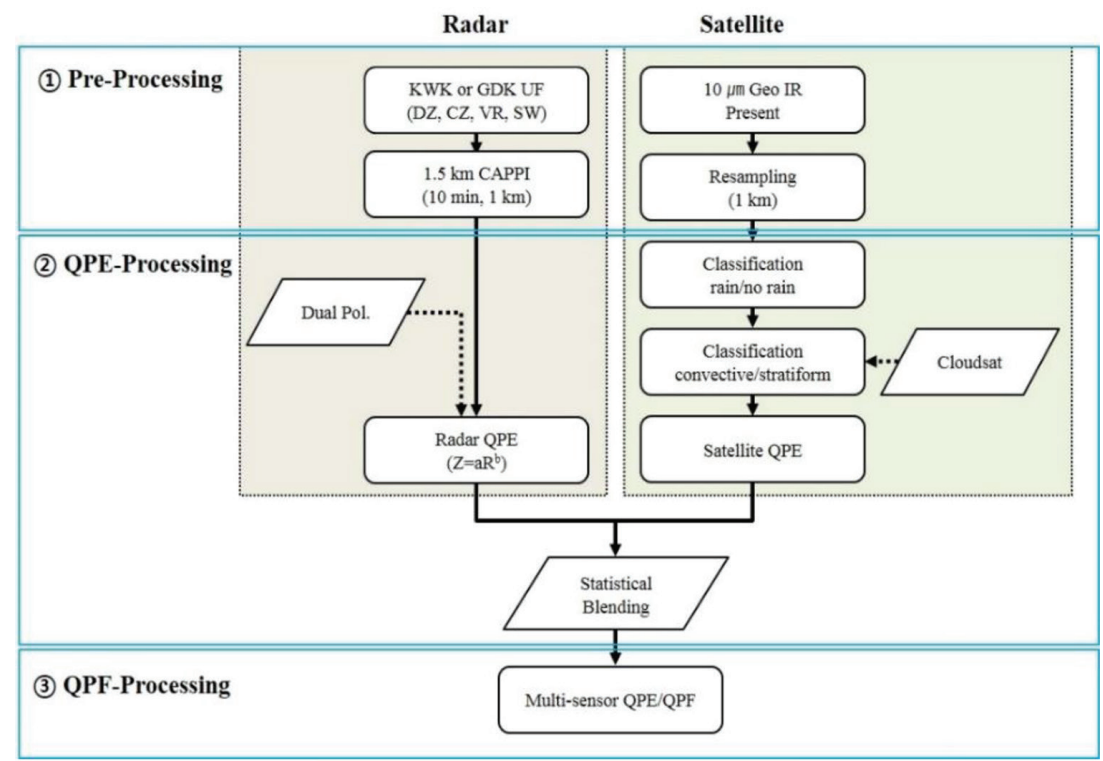

Figure 3: Short-term rainfall forecasting. 
Simplification of sewer network except river area is divided by four steps: (i) check initial condition, (ii) calculate watershed area, (iii) division of branch and main lines, and (iv) calculate parameter.

(i) Check initial condition is classified as starting point of sewer, dividing point of sewer, confluent point of sewer and outlet of sewer. Calculate watershed area can be calculated by adding starting point of sewer to outlet of sewer. The sewer 1 is starting of sewer, the sewer 2, 3 are dividing point of sewers, the sewer 6,7 are confluent point of sewers and the sewer 8 is outlet of sewer as shown in Figure 4. In the case of branch line, a sewer pipe having the large discharge area is selected as a main pipe of branch, and the other pipes were set as partial pipe of branch. If they have same discharge area, a pipe located at front side is defined as the main pipe.

(ii) Calculate watershed area can be calculated by adding starting point of sewer to outlet of sewer. (iii) Sewer network are branch line and main line. If the product of runoff coefficient and planned drainage area is more than 12 hectare, it is defined as main line, otherwise it is set as branch line. (iv) Calculate parameters of SWMM models used in simplification process are Subcatchment (Imperv, Slope), Subarea (N-Imperv, N-Perv, S-Imperv, S-Perv),

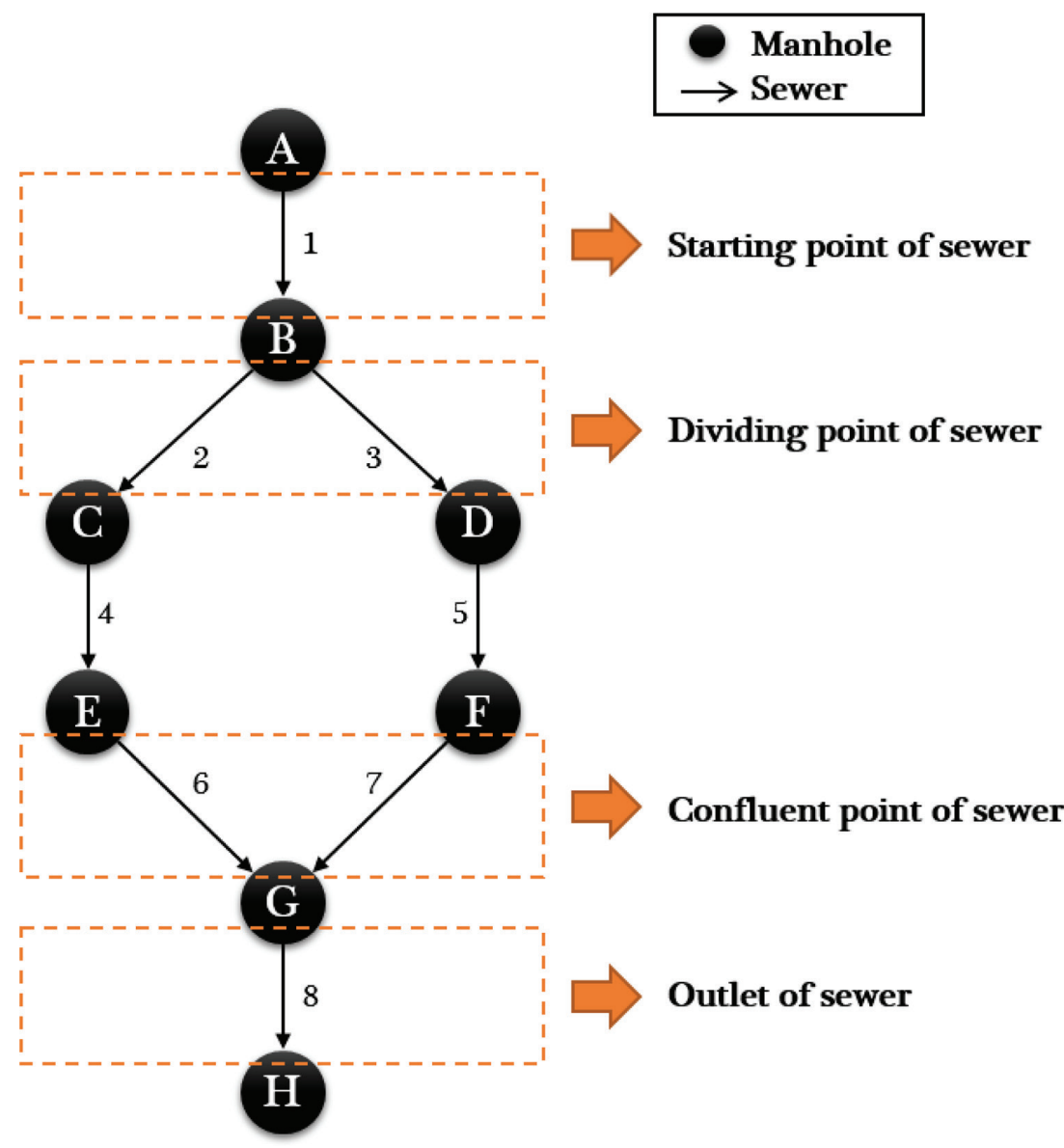

Figure 4: Check initial condition. 
Infiltration (Max Rate, Min Rate, Decay, Drytime) and Conduits (Roughness). At last, Sewer network simplification consist of sewer networks by calculate reasonable watershed area. A node or link less than 12 hectare of cumulative watershed area as a basis for dividing branch and main line are deleted in the simplification process, so the parameters of the node and link to be deleted are calculated by applying area weighting. Through this process, a simplified sewer network can be constructed.

Figure 5a presents the sewer network of test basin before simplification. Figure 5b presents the result of sewer network simplification based on cumulative basin area.

The sewer network has simplified by $85 \%$ and the simulation time of rainfall-runoff model is reduced by $90 \%$ as shown in Table 1 . This means when the runoff analysis is carried out

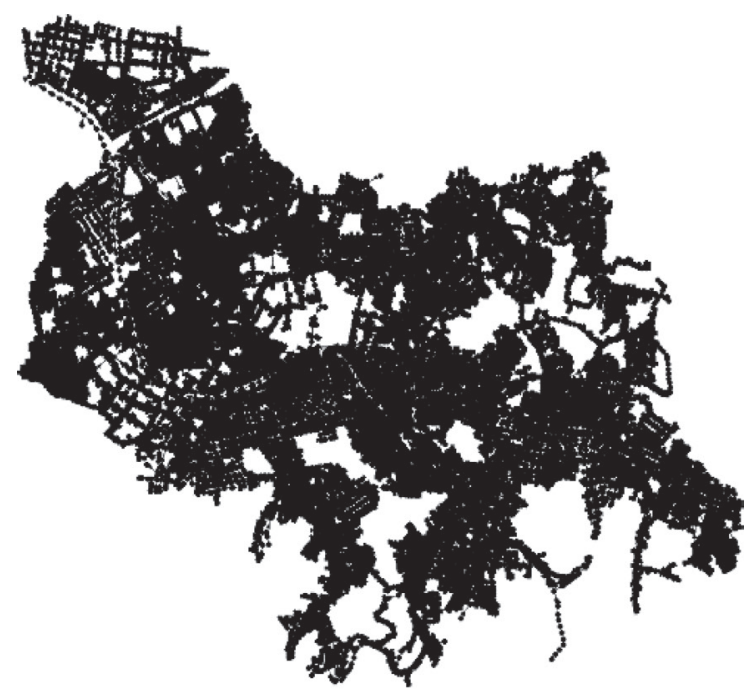

(a)

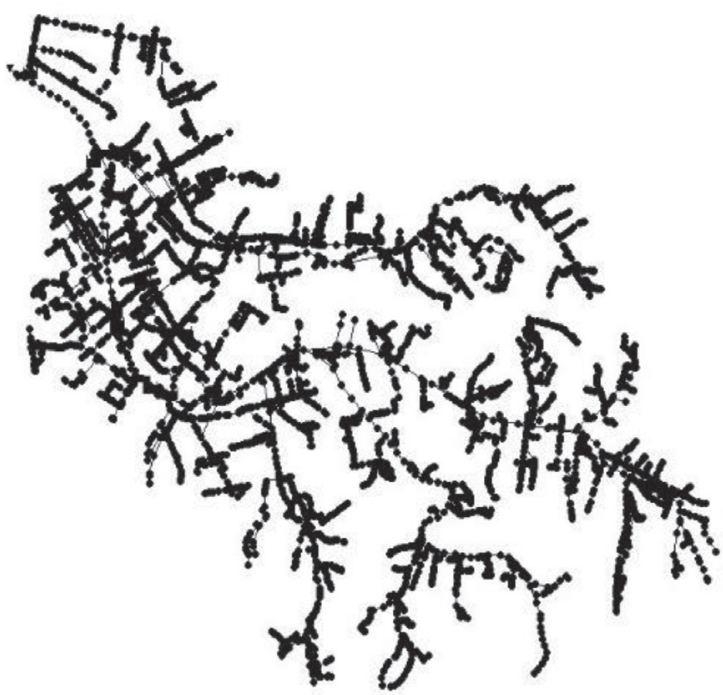

(b)

Figure 5: Simplification technology of sewer network. 
Table 1: Comparative simulation time according to the simplified.

\begin{tabular}{llll}
\hline & \multicolumn{2}{l}{ Simulation time } & \\
\cline { 2 - 4 } $\begin{array}{l}\text { Duration of } \\
\text { rainfall }\end{array}$ & (a) Total sewer network & $\begin{array}{l}\text { (b) Simplified sewer } \\
\text { network }\end{array}$ & $\begin{array}{l}\text { (c) Reduction rate of } \\
\text { time (\%) }\end{array}$ \\
\hline $60 \mathrm{~min}$ & $00: 11: 00$ & $00: 01: 12$ & 89.1 \\
$180 \mathrm{~min}$ & $00: 40: 00$ & $00: 03: 37$ & 91.0 \\
$360 \mathrm{~min}$ & $01: 20: 21$ & $00: 07: 24$ & 90.8 \\
\hline
\end{tabular}

using the simplified sewer network for real-time urban flood forecasting, it calculates $90 \%$ of the golden time compared to the entire network due to short simulation time.

There is a classification in accordance with utilization between total sewer network and simplified sewer network. Simplified sewer network (Fig. 5b) used real-time urban flood forecast. Total sewer network (Fig. 5a) is used as a rainfall-runoff model for inundation analysis in inland. It used 2D Analysis which performed by interlocking SWMM with TUFLOW. In the final step, different scenarios (Fig. 6a-d) using total sewer network, constructed the maximum inundation area database according to various rainfall and durations. Various 2D database used real-time flood forecasting due to the reason that real-time $2 \mathrm{D}$ takes a longer time to process.

\section{CONCLUSION}

As part of the measures to deal with the increase of inland flood damage, it is necessary to build a systematic city flood prevention system that systematizes technology to quantify flood risk as well as flood forecast considering both inland and river water. This Combined

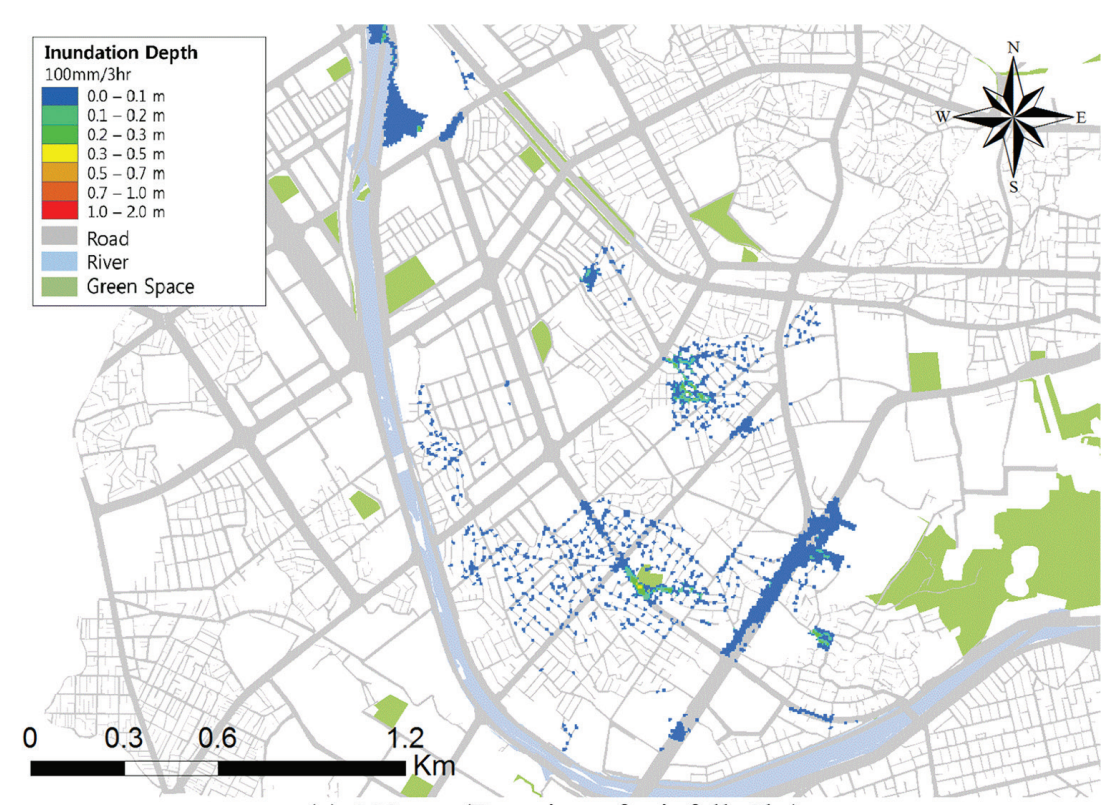

(a) $100 \mathrm{~mm}$ (Duration of rainfall: $3 \mathrm{hr}$ )

Figure 6: Maximum inundation area database. 


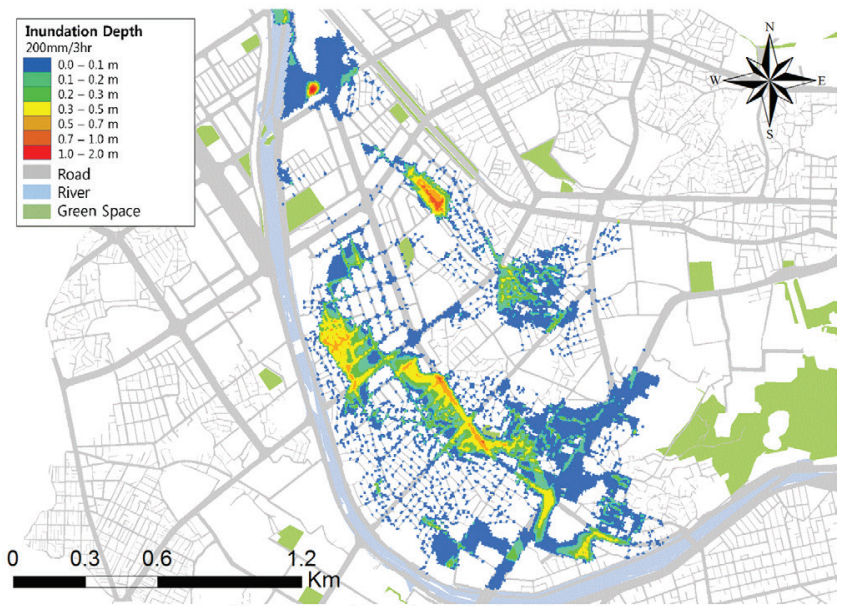

(b) $200 \mathrm{~mm}$ (Duration of rainfall: $3 \mathrm{hr}$ )

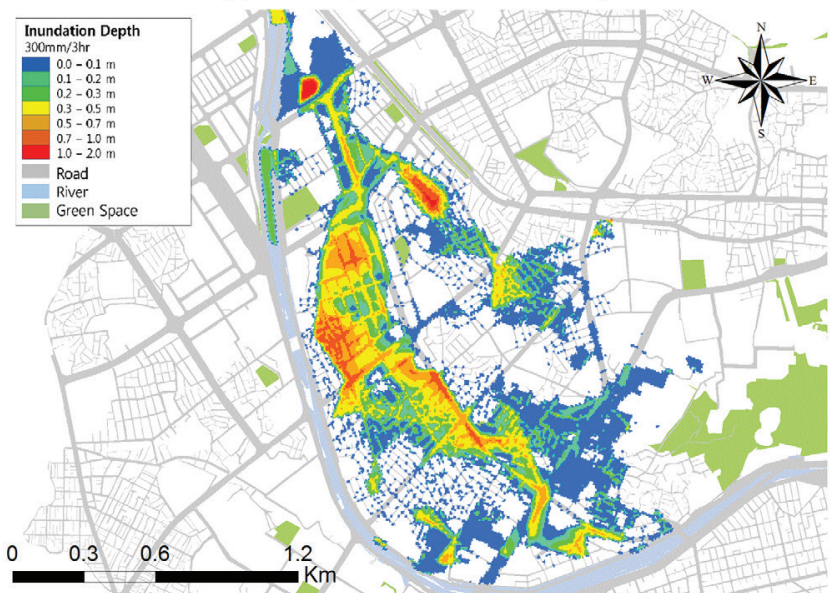

(c) $300 \mathrm{~mm}$ (Duration of rainfall: $3 \mathrm{hr}$ )

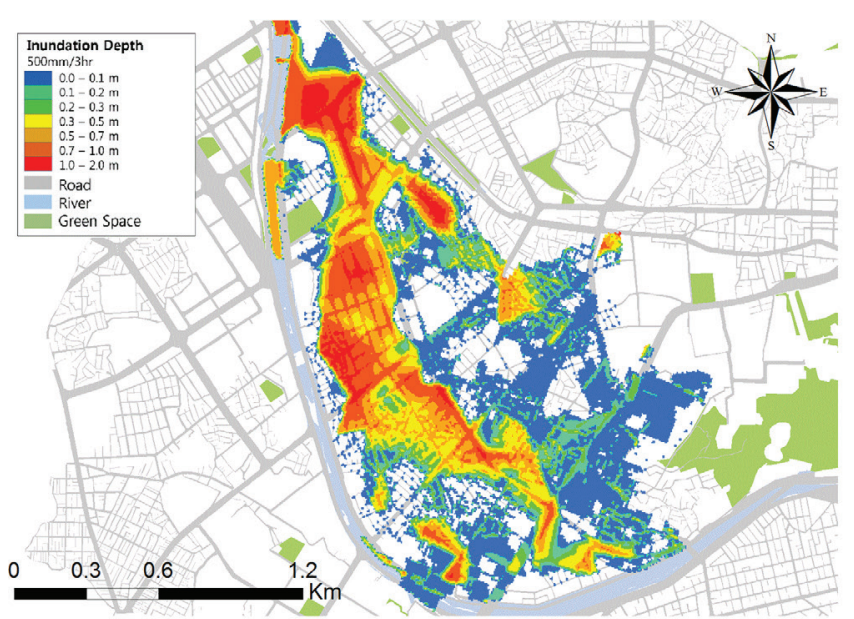

(d) $500 \mathrm{~mm}$ (Duration of rainfall: $3 \mathrm{hr}$ )

Figure 6: (Continued) 
Inland-River Flood Analysis System conducts prediction on flash rain or short-term rainfall by using radar and satellite information and performs prompt and accurate prediction on the inland flooded area. It also supports synthetic decision-making for prevention through realtime monitoring. Climatic conditions in the 21st century which can cause disasters may happen to us anytime in the future. The Korean Peninsula has no exception. Although we cannot prevent damage from typhoons or localized heavy rain, we can minimize that damage with accurate and prompt forecast and a prevention system. To realize this, it is demanded to integrated decision-making system to forecast super typhoons or sudden rainfalls and monitor them in real time, which can generate forecast or alarms.

\section{ACKNOWLEDGEMENTS}

This research was supported by a grant (16AWMP-B066744-04) from Advanced Water Management Research Program (AWMP) funded by Ministry of Land, Infrastructure and Transport of Korean government.

\section{REFERENCES}

[1] Kim, J.S. \& Jain, S., Precipitation trends over the Korean peninsula: typhoon-induced changes and a typology for characterizing climate-related risk. Environmental Research Letters, 6, p. 034033, 2011. https://doi.org/10.1088/1748-9326/6/3/034033

[2] Kim, J.S., Li, R.C.Y. \& Zhou,W., Effects of the Pacific-Japan teleconnection pattern on tropical cyclone activity and extreme events over the Korean peninsula. Journal of Geophysical Research, 117(D18), p. 109, 2012. https://doi.org/10.1029/2012jd017677

[3] Kim, S.M., Tachikawa, Y. \& Takara, K., Recent flood disasters and progress of disaster management system in Korea. Annuals of Disaster Prevention Research Institute Kyoto University, 50B, pp. 15-31, 2007.

[4] Park, B.C., Oh, K. S. \& Lee, D. W., Flood damage prediction for provincial governments in Korea based on climate change scenarios. International Journal of Environmental Science and Development, 8(6), pp. 435-441, 2017.

https://doi.org/10.18178/ijesd.2017.8.6.993 